\title{
UM OLHAR SOBRE O MARKETING DE UM ESPAÇO CULTURAL: CASO CIRCO DA DONA BILICA
}

\section{A LOOK ON THE MARKETING OF A CULTURAL SPACE: DONA BILICA CIRCUS CASE}

\author{
Márcio Batista de Miranda \\ Doutorando em Engenharia e Gestão do Conhecimento pela Universidade Federal de Santa Catarina (EGC/UFSC) \\ Especialista em Marketing e Gestão Estratégica pela Universidade Cândido Mendes (UCAM) \\ Professor das Faculdades Borges de Mendonça \\ E-mail: marciobmiranda@gmail.com
}

\section{Fernanda Will}

Graduada em Administração pela Faculdade Decisão.

Estudante do Curso Técnico em Eventos pelo Instituto Federal de Santa Catarina

Produtora Cultural no Circo da Dona Bilica.

E-mail: fe.fernandawill@gmail.com

\section{Richard Perassi Luiz de Sousa}

Doutor em Comunicação e Semiótica pela Pontifícia Universidade Católica de São Paulo (PUC)

Mestre em Educação pela Universidade Federal de Mato Grosso do Sul (UFMG)

Professor associado da Universidade Federal de Santa Catarina (UFSC)

Email: perassi@cce.ufsc.br

\section{Carlos Augusto Monguilhott Remor}

Doutor em Engenharia de Produção pela Universidade Federal de Santa Catarina (UFSC)

Mestre em Literatura pela Universidade Federal de Santa Catarina (UFSC)

Professor da Universidade Federal de Santa Catarina (UFSC)

E-mail: remor@me.com.br

\section{RESUMO}

Atualmente, o mercado cultural no Brasil vem, ainda que a passos curtos, buscando seu lugar. A economia criativa, a exemplo dos espaços culturais, representa 2,6\% do PIB brasileiro. Portanto, a adoção de estratégias para a conquista e a manutenção no mercado, se torna essencial para a sobrevivência de muitas empresas hoje. Este artigo tem como objetivo investigar como podem ser percebidas as práticas de marketing do Circo da Dona Bilica. O estabelecimento desse olhar aborda as estratégias e ações adotadas pelo Circo da Dona Bilica em seu processo de consolidação como 
um espaço cultural no mercado de Florianópolis. As dificuldades apresentadas ao se fazer da cultura um produto de consumo também são discutidas. A pesquisa é de natureza aplicada, qualitativa, exploratória e descritiva, utilizando o método dedutivo. Os procedimentos técnicos utilizados foram o levantamento bibliográfico, a pesquisa documental e o estudo de caso. A análise do espaço e das práticas permitiu observar o Circo da Dona Bilica como um espaço cultural que considera as estratégias como passo fundamental para a empresa se posicionar como um centro de excelência no estado de Santa Catarina.

Palavras-chave: Práticas de marketing. Marketing estratégico. Circo da Dona Bilica. Marketing cultural.

\begin{abstract}
Currently, the cultural market in Brazil has, although the short steps, seeking its place. The creative economy, like the cultural venues, is $2.6 \%$ of the GNP. Therefore, the adoption of strategies for the achievement and maintenance market is essential for the survival of many businesses today. This article aims to investigate how Dona Bilica Circus marketing practices can be perceived. The establishment of and this glance discusses the strategies and actions taken by Dona Bilica Circus in its consolidation as a cultural space in Florianópolis market. Difficulties in turns culture to a consumer product are also discussed. The research is of an applied nature, qualitative, exploratory and descriptive, using of the deductive method. The technical procedures used were literature, documentary research and case study. The analysis of space and practices allowed us to observe the Circus of Dona Bilica as a cultural space that considers the strategies as a key step for the company to position itself as a center of excellence in the state of Santa Catarina.
\end{abstract}

Keywords: Marketing Practices. Strategic marketing. Dona Bilica Circus. Cultural marketing.

\title{
1 INTRODUÇÃO
}

A indústria da cultura em massa, como cinema, TV, música popular, entre outros, hoje representa uma grande influência na vida de muitas pessoas. Giddens (2005, p. 375) em seu livro cita sobre um estudo da Escola de Frankfurt que toda essa indústria massiva "enfraquece a capacidade de os indivíduos desenvolverem um pensamento crítico e independente”.

Linguagens - Revista de Letras, Artes e Comunicação ISSN 1981-9943 Blumenau, v. 9, n. 2, p. 190-210, mai./ago. 2015 
Giddens (2005) afirma, ainda, que há uma queda da esfera pública que pode ser conceituada como a criação de debates públicos, que auxiliam na formação de opiniões. Estas constatações podem denotar extensas discussões em busca de soluções. Pode-se assentir que uma das possibilidades de preencher estas lacunas sociais seja o estímulo e o fomento à espaços culturais, tais como teatros, cinemas, circos, galerias, entre outros. Quando um destes espaços é bem trabalhado, ele pode desenvolver a imagem positiva na mente das pessoas, fazendo com que sejam atraídas. No caso de Florianópolis, um exemplo é o Circo da Dona Bilica.

E o ponto chave desta reflexão é o questionamento acerca de: como podem ser percebidas as práticas de marketing do Circo da Dona Bilica?

Um olhar sobre as práticas de marketing do Circo fornecem uma visão exploratória do tema. E é relevante criar a percepção de que a cultura deve ter um papel fundamental, e que as opções de entretenimento não podem ser restritas a shopping centers ou peças de teatro da moda. Então, como vender cultura? Faz-se necessário a abertura de uma nova janela, que fará o espectador refletir, rir, chorar, por assimilar as situações que estão em cima do palco com a sua realidade, e assim, fomentar o desejo do mesmo pela cultura.

O objetivo geral deste trabalho é verificar como podem ser percebidas as práticas de marketing do Circo da Dona Bilica. Apresenta como objetivos específicos: (1) caracterizar a empresa como uma organização cultural; (2) descrever as ações de marketing da empresa; (3) analisar a imagem de marketing do Circo como espaço Cultural.

A estrutura deste artigo está composta em partes. Nesta primeira parte são apresentadas a delimitação do tema, a problemática da pesquisa e a possível barreira na introdução da cultura como fomento para crescimento do indivíduo, a justificativa e os objetivos, geral e específicos. No desenvolvimento do artigo, compreende a fundamentação teórica sobre marketing e posicionamento, e marketing para organizações culturais; a metodologia, caracterizando como se dá a pesquisa e descrição do desenvolvimento do trabalho; e a análise e discussão dos resultados, onde são apresentadas as estratégias e as ações de marketing, bem como o histórico do Circo da Dona Bilica. A terceira parte é a conclusão onde aborda as considerações finais de toda a pesquisa. 


\section{FUNDAMENTAÇÃO TEÓRICA}

Para compreensão do problema de pesquisa, buscou-se informações de diversos autores, muitos deles tidos como renomados na área de marketing. A fundamentação teórica é condição importante para encontrar as possíveis respostas que possam ajudar no melhor entendimento do problema de pesquisa.

\subsection{CONSIDERAÇÕES INICIAIS SOBRE MARKETING}

O marketing muitas vezes é visto como o setor exclusivo apenas às divulgações/ propaganda da empresa, porém este conceito é restrito, uma vez que para a American Marketing Association, o marketing é "o processo de planejar e executar a concepção, a determinação do preço, a promoção e a distribuição de ideias, bens e serviços para criar trocas que satisfaçam metas individuais e organizacionais" (KOTLER, 2000, p. 31).

$\mathrm{O}$ mercado consegue atender as necessidades e desejos dos clientes, mediante a oferta $\mathrm{e}$ negociação, de acordo com a disponibilidade que o cliente tem em gastar com seu produto ou serviço. Também pode-se conceituar:

Marketing é a área do conhecimento que engloba todas as atividades concernentes às relações de troca, orientadas para a satisfação dos desejos e necessidades dos consumidores, visando alcançar os objetivos da empresa e considerando sempre o meio ambiente de atuação e o impacto que essas relações causam no bem-estar da sociedade (LAS CASAS, 1987, p. 30).

Numa descrição mais completa, Las Casas (1987) complementa sobre além do atendimento das necessidades e desejos, isto deve estar direcionado ao mercado de atuação, e visando quais as consequências perante a sociedade. Para compreender como surgiram tais conceitos, é importante contextualizar o marketing, observando sua evolução histórica.

A compreensão do marketing, não basta por si só, para atuação no mercado. O profissional de marketing deve também considerar a administração de marketing. De acordo com Kotler e Amstrong (2004) a administração de marketing diz respeito à analisar, planejar, implementar e controlar programas desenvolvidos, para que a organização possa atingir seus objetivos organizacionais. 
Para realizar seus objetivos, a organização cria, constrói e mantém trocas benéficas com os seus compradores alvos. Os processos de marketing são essenciais às atividades de administração de marketing, como elencados seguir:

- Planejamento de marketing: de acordo com Honorato (2004, p.59), "é a base para toda estratégia mercadológica. Influencia diretamente nas decisões sobre estratégias de produto, preço, distribuição e promoção."

- Organização de marketing: numa visão holística, organizar para Chiavenato (2007, p. 191) é reunir um grupo de pessoas em junção dos recursos organizacionais, afim de que se possa atingir os objetivos.

- Ações de marketing: as ações que serão tomadas mediante planejamento devem atender aos questionamentos: “[...]o que será feito? Quando? Quem é o responsável? Quanto irá custar?” (LIMA et al, 2003, p. 130).

- Controle de marketing: “o processo de controle consiste em estabelecer níveis de desempenho pretendido e o realizado" (HONORATO, 2004, p. 71).

Miyashita (2006) afirma que o marketing está presente nos âmbitos operacional, tático e estratégico. Fernandes (2003) afirma que o marketing operacional, mesmo não tendo uma relação direta com ações estratégicas que visem a longevidade do negócio, é tão importante quanto, pois é através dele, que há uma maior proximidade com o cliente. A partir do marketing operacional, a empresa pode ter a "[...] percepção dos consumidores em relação ao produto ofertado e aos concorrentes, de forma a medir a força da empresa e o posicionamento que ocupa na mente das pessoas" (FERNANDES, 2003, p. 56).

Assim, a empresa consegue através de todo o seu sistema de gestão, aprimorar a qualidade no fornecimento do seu produto/serviço, por meio do feedback que o cliente fornece a empresa no nível operacional.

O marketing tático, por sua vez, apresenta uma postura mais agressiva, no sentido da maior proximidade com setor de vendas e atendimento. Por ter acesso a resultados e informações de mercado, o marketing tático apresenta projetos de atuação, para resolução de problemas com soluções pontuais, como decisões voltadas a precificação e suas políticas de vendas, com os serviços de pós-venda e também com a gestão dos canais de distribuição e parceiros 
(MIYASHITA, 2006). Contribui significativamente para o marketing estratégico. Já o marketing estratégico, esta direcionado para as atividades de longo prazo, usando estratégias, para diferenciação, valor, investimento em imagens de marca (COBRA, 2009). Ela busca a longevidade do negócio, a otimização dos recursos.

\subsection{MARKETING ESTRATÉGICO}

Em se tratando de marketing, Kotler e Armstrong (2003) abordam que o mercado atual vive em constante mudança, principalmente devido aos fatores tecnológicos e a globalização. E que a adoção da melhor estratégia hoje, pode ser o fracasso de amanhã. O marketing estratégico, não deve apenas trabalhar com a administração da demanda, ele também deve buscar quais são as oportunidades de mercado, quais as medidas, que empresa e concorrência adotam, entre outros fatores, que servirão de base para elaborar o planejamento, e entender melhor o seu ambiente.

O ambiente de marketing de uma organização "é constituído de participantes e forças externas a ele que afetam a capacidade da administração de marketing de desenvolver e manter bons relacionamentos com seus clientes-alvo" (KOTLER; ARMSTRONG, 2003, p. 61).

Para Cobra (2009, p. 14) a análise do ambiente de marketing está relacionada com o apontamento das forças no mercado, que podem ser de ordem política, econômica, social, da sociedade, concorrência, entre outros. E qual a interação destas forças com a organização. Deste modo, a empresa consegue responder aos questionamentos: como, o que, onde, quando, por que... Estimando a sua demanda de mercado e as possibilidades de consumo.

Silva et al (2006, p. 16) citam que o planejamento estratégico, é o “[ [... processo gerencial voltado a criar a adequação dos objetivos e recursos da empresa às mudanças de oportunidades de mercado". Agregar o marketing a este conceito, é orientar a empresa ao mercado, visando sua maior competitividade. O estabelecimento de estratégias e objetivos, neste caso, devem estar em sintonia com os recursos que a empresa dispõe.

Silva (2001, p. 421) aborda que cultura Organizacional é o compartilhamento de valores, crenças, normas e hábitos entre os membros da organização. Tais comportamentos regem a interação das ações dentro da organização. Acrescentando, Chiavenato (1999, p. 602) cita que a Cultura sofre mudanças, e empresas que insistem em não mudar sua cultura, ficam presas a padrões ultrapassados, portanto, deve haver uma evolução da cultura organizacional. 
Se uma empresa em teoria não deve ficar presa a padrões ultrapassados, no sentido de atraso perante as necessidades do mercado. A definição do negócio, não atua como um limitador das atividades desempenhadas, mas como "[...] catalisador dos esforços da organização para manter-se em movimento atendendo aos clientes atuais e preparando-se para atender aos clientes futuros" (SILVA, et al, 2006. p. 28). Neste caso, a sua aplicação pode ocorrer sob critério técnico e percepção de mercado:

- Critério técnico: apresenta uma orientação mais estratégica, e de modo sucinto, ela deverá responder questionamentos como: Qual a sua demanda? De quem são esses desejos, necessidades, expectativas? (CORREA, et. al., 2009).

- Percepção de mercado: a imagem que a organização quer passar, irá determinar o posicionamento, a percepção para o cliente do principal benefício que ele espera do produto. Um exemplo é a Nike, que vende tênis, mas numa visão ampliada do negócio a empresa vende atitude (CORREA, et. al., 2009).

Kotler e Armstrong (2004) citam que a segmentação, definição de mercado alvo e posicionamento de mercado são elementos estratégicos no marketing. A segmentação de mercado pode ser conceituada como a divisão do mercado de atuação, por meio da busca de pontenciais compradores (HONORATO, 2004, p. 150). Já a definição do mercado-alvo diz respeito a avaliação de cada um dos segmentos existentes, e a partir disto a empresa escolhe um ou mais para atender (KOTLER; ARMSTRONG, 2004). E Pride e Ferrel (2001, p. 217) citam que posicionar é o modo, que faz crer que o produto apresenta as características que o cliente mais necessita, ou seja, um conceito na mente do cliente. O posicionamento será abordado de modo mais apurado, afim de auxiliar na construção da análise.

\subsection{POSICIONAMENTO}

O posicionamento de mercado diz respeito à construção da imagem que o produto representa na mente do consumidor, e o diferencia da concorrência. Ela pode oferecer uma valor mais baixo do que a concorrência, ou então oferecer um valor superior, mas que contenha benefícios que justifiquem esta diferença (KOTLER; ARMSTRONG, 2004). O posicionamento, como uma das estratégias de Marketing, de acordo com Kotler e Keller (2006, p. 22) são os 
diferenciais e/ou benefícios que uma marca representa na mente dos clientes. Ocorre através da prestação do serviço, e que são definidos as formas de promoção, os preços a serem praticados, e lugares a serem vendidos. Diz respeito ao diferencial que uma marca que comercializa o mesmo produto que o concorrente, estabelece na mente do cliente,

Ainda agregando aos conceitos anteriores, Honorato (2004, p.161) cita que: "posicionar produto de maneira clara significa para a empresa a adequação ao segmento de mercado escolhido. O posicionamento do produto é o início do processo operacional e estratégico". A partir da explanação destes conceitos, é possível saber quais são seus pressupostos, e como se da sua implementação. Pride e Ferrel (2001, p. 217) afirmam que o resultado do posicionamento consiste em criar esta imagem na mente do consumidor, em relação à concorrência. Os compradores têm por hábito agrupar os produtos na mente, de modo que facilite no processo de compra. Deste modo, quando se posiciona eficazmente um produto, cria-se o conceito pretendido na mente do consumidor.

As estratégias competitivas adotadas levam em conta as necessidades dos clientes e as ações tomadas pela concorrência. Sendo neste ultimo caso, uma análise do concorrente, comparando o valor e satisfação para o cliente através dos produtos, preços, canais e promoção, com os de outros concorrentes. Como opções de estratégias as empresas podem adotar ser líder de mercado, como o próprio nome diz, são as líderes nos segmentos de atuação. Há também as desafiantes de mercado, que atacam as líderes para obter maior participação de mercado. As seguidoras de mercado, buscam a estabilidade e adotam em muitos casos as estratégias da concorrência. Por fim, as buscadoras de nichos de mercado, que procuram pelos nichos de mercado, onde a concorrência não atende bem, ou simplesmente ignora (KOTLER; ARMSTRONG, 2004).

Cobra (2009, p. 10) afirma que o "processo de adoção de estratégias de marketing consiste de quatro elementos denominados composto de marketing (marketing mix). Os elementos são: produto, preço, promoção e distribuição". Ou seja, estas quatro variáveis serão controladas e moldadas, de modo que atendam a demanda de um produto. Fazem parte do composto:

- Produto: "bem físico ou um serviço com um conjunto de características que é destinado a um segmento de mercado identificado" (FERREIRA; REIS; SERRA, 2010, p. 371).

- Praça: de acordo com Kotler e Keller (2006) a praça, ou também canal de distribuição, são as atividades que tornarão o produto disponível ao consumidor. 
- Preço: é o valor monetário destinado para um bem ou serviço. A definição do preço é algo complexo e difícil (FERREIRA; REIS; SERRA, 2010, p. 371).

- Promoção: é o processo de comunicação por meio da elaboração de estratégias com o cliente que busca influencia-lo no estágio da compra (HONORATO, 2004, p. 7).

Quando bem entrosadas, permitem que a empresa consiga criar “[...] valor para os clientes e alcançar os objetivos da organização" (SANTIAGO, 2009, p. 119). Fortalecendo deste modo, o posicionamento do seu mercado-alvo.

Tais estratégias serão importantes na criação de uma estrutura de referência competitiva conforme Kotler e Keller (2006, p. 305), de modo como pode ser diferenciada um produto de outro, identificando o mercado alvo e a concorrência, criando associações em relação a pontos de paridade e de diferença.

Surge então a vantagem competitiva, como posicionamento de valor superior ao da concorrência, Kotler e Armstrong (2004, p. 191) também citam que “[...] posições sólidas não podem ser construídas em cima de promessas vazias. Se a empresa posicionar seu produto como algo que oferece a melhor qualidade e serviço, ela deve entregar a qualidade e o serviço prometidos". Assim, esta entrega de qualidade e serviço, quando bem sucedida, proporciona a proposição de valor de marca.

Enquanto o posicionamento é a imagem que diferencia um produto/serviço na mente do cliente em relação à concorrência (KOTLER; KELLER, 2006, p. 322), a arte é um elemento da cultura capaz de agregar valor a sociedade, e subentende-se que também pode adotar estratégias que auxiliem em seu posicionamento mercadológico dentro desta sociedade.

\subsection{MARKETING PARA ORGANIZAÇÕES CULTURAIS}

A Cultura conforme Giddens (2005, p.38) é representada como os aspectos herdados e aprendidos conforme o passar das gerações, e que são compartilhados com os indivíduos nos quais possuem relação. Estes outros indivíduos também tem seus aspectos culturais, e o processo de cooperação e comunicação, permite compreender a diversidade cultural que pode haver numa mesma comunidade. 
A arte, sendo um dos sentidos da cultura, é definida como "[...] uma manifestação do espírito humano, materializada mediante habilidades e inclinações que repercutem na música, dança, literatura, pintura, enfim, em qualquer atividade de cunho estético desenvolvida pelo homem" (VALENTE et al, 2007, p. 1).

Fazendo um apanhado histórico, há um crescimento no mercado cultural no Brasil desde a criação do Ministério da Cultura na década de 80. As organizações culturais tiveram que ampliar seu foco no campo formal das artes, folclore e patrimônio, para também o campo das ciências sociais, o mundo dos negócios, do gerenciamento, da distribuição e do consumo de produtos e serviços (MARCO, 2007).

Esta ampliação de foco surge da necessidade de profissionalizar e capacitar profissionais na área, pois nota-se a nova relação de custo-benefício entre cultura e mercado compreendendo-as como produtivas em prol do alicerce do desenvolvimento social, regional e nacional (MARCO, 2007).

Por isto, o mercado cultural se vincula a uma fonte de recursos, que sustente a criação, a produção cultural, como a arrecadação através da receita gerada pela venda de ingressos aos espectadores. O financiamento da cultura permite a pesquisa da linguagem, "flerta com o novo, discute o estabelecido, subverte e choca. E é, portanto, indiscutivelmente vanguarda" (ALMEIDA, 2006, p. 9).

O objetivo de muitas organizações culturais hoje deixa de ser o público e a própria arte, e passa a ser o mercado, na busca pela sobrevivência (HOFFMANN; SILVA; DELLAGNELO, 2009). O entendimento do funcionamento das regras de mercado parece ser uma questão de sobrevivência para muitas organizações deste campo, e o marketing torna-se um dos instrumentos de trabalho mais utilizado. Propor estratégias que atendam a estes perfis é importante para atrair o público e posicionar a empresa. O profissional de marketing em organizações culturais são representados pelos produtores culturais, devido ao fato de estas organizações na sua maioria ser de porte pequeno, e não ter um profissional exclusivo para esta área. Para a efetividade das suas atividades, a criatividade e os recursos são os elementos essenciais da transformação que sustenta a produção artística (ALMEIDA, 2006, p. 8).

Este profissional enfrenta um desafio, em relação ao paradoxo da definição do que é o Marketing e a base de toda a produção cultural, conforme descrito por Neto (2006, p. 6). O Marketing conforme descrito anteriormente, desenvolve estratégias para atendimento das 
necessidades e desejos de um mercado-alvo. Enquanto o artista em sua produção cultural está atendendo a si mesmo, a sua necessidade e desejo.

O profissional deve compreender este paradoxo do marketing e arte, e assim buscar o melhor modo de atender este comportamento híbrido e aplicar o composto de marketing na busca da construção de uma imagem atrativa das atividades artístico-culturais. Tal composto será aplicado de modo: (1) o produto/serviço (exemplo: apresentação cultural, um show musical, entre outros); (2) a praça, responde ao questionamento onde está o meu espectador?; (3) o preço pode corresponder ao valor de um ingresso. A receita tem que condizer com a adequada viabilização e sustento do trabalho do artista; e (4) a promoção, como será realizada a comunicação que irá levar o público ao artista (NETO, 2006, p. 6). A totalidade da aplicação do composto é essencial como estratégia ao profissional nas atividades de marketing.

\section{METODOLOGIA}

A metodologia significa escolher um caminho, de que modo será realizada a pesquisa. A pesquisa conforme Cruz e Ribeiro (2003, p.11) diz respeito a "[...] buscar compreender a forma como se processam os fenômenos observáveis, descrevendo sua estrutura e funcionamento".

A fonte de toda a pesquisa está relacionado na tentativa de compreender um processo, ou problema, entre outros, através da descrição de hipóteses, que respondam a ao processo/problema. Fortalecendo este conceito de pesquisa, pode-se afirmar que:

A finalidade da pesquisa científica não é apenas um relatório ou descrição de fatos levantados empiricamente, mas o desenvolvimento de um caráter interpretativo, no que se refere aos dados obtidos. Para tal, é imprescindível correlacionar a pesquisa com o universo teórico, optando-se por um modelo teórico que sirva de embasamento à interpretação do significado dos dados e fatos colhidos ou levantados (MARCONI e LAKATOS, 2001, p. 110).

A interpretação das premissas ou pressupostos da pesquisa científica, não está embasada em experiências vividas, mas sim, em uma fundamentação teórica. Observa-se, neste artigo, a percepção das estratégias de marketing de um espaço cultural a partir de suas ações de comunicação. Desta forma, o olhar sobre as práticas de marketing se dá a partir da descrição dos fatos ocorridos na própria organização, bem como de sua definição. Verifica-se, portanto, se o que está definido na organização é o que se apresenta em suas ações. 
Em se tratando da abordagem como problema, a mesma é classificada como qualitativa. Isto porque esta relacionado com a aquisição de informações no sentido de nortear a solução do problema, onde o mesmo não pode ser mensurado em números, e sim em hipóteses resultantes da análise das premissas da bibliografia, com o problema. Também é importante citar que "o ambiente natural é a fonte direta para coleta de dados e o pesquisador é o instrumento-chave" (SILVA; MENEZES, 2005).

Os objetivos desta pesquisa caracterizam-na como exploratória e descritiva. No tocante a pesquisa exploratória pode-se conceituar como a busca pela familiaridade com o tema, através de levantamento bibliográfico, análise de exemplos, entre outros. Esta busca permitirá tornar explícito o problema, e/ou assim poderá ser possível a construção de hipóteses (SILVA; MENEZES, 2005).

Já a pesquisa descritiva, é a explanação das características de determinada população ou fenômeno, há de se considerar também como o estabelecimento de relações entre variáveis. No artigo presente assumiu a forma de Levantamento, averiguar as informações essenciais para a contribuição na elaboração de hipóteses.

O método de pesquisa é dedutivo conforme conceituado por Marconi e Lakatos (2001, p. 106) como " [...] partindo das teorias e leis, na maioria das vezes prediz a ocorrência dos fenômenos particulares (conexão descendente)". Muitas respostas para as hipóteses levantas podem ser respondidas através dos levantamentos bibliográficos.

A natureza da pesquisa deste artigo é básica. Silva e Menezes (2005) destacam que este tipo de pesquisa é aquela que a partir dos conhecimentos obtidos, não apresentam uma previsão para a sua aplicação. Os procedimentos descritos podem ter sua aplicação a outras organizações, que desejam obter informações quanto a percepção das práticas de uma empresa.

Os procedimentos técnicos deste artigo que foram usados são classificados em pesquisa bibliográfica, documental e estudo de caso. De acordo com Silva e Menezes (2005) a conceituação destes procedimentos técnicos podem ser: a pesquisa bibliográfica é o uso de material já publicado, como livros e artigos. A pesquisa documental é o levantamento de material que não passaram por um tratamento analítico, que o levaria a ser uma pesquisa bibliográfica. E o estudo de caso é o estudo profundo do objeto de pesquisa de modo que se obtenha o seu detalhado conhecimento. 


\section{ANÁLISE E DISCUSSÃo DE RESULTADOS}

O problema de pesquisa sobre como podem ser percebidas as práticas de marketing do Circo da Dona Bilica, não pode ter suas conclusões apenas da fundamentação teórica. Para o melhor discernimento, a etapa de análise do Circo da Dona Bilica é importante para saber se as ações já adotadas condizem com o que a teoria coloca como o que pode ser fundamental no marketing de uma empresa.

\subsection{O CIRCO DA DONA BILICA}

O Circo da Dona Bilica é um empreendimento da companhia Pé de Vento Teatro, uma companhia de teatro com fundação em junho de 1999. O espaço tem como anfitriões a Dona Bilica, a famosa "manezinha" interpretada pela atriz Vanderléia Will, e seu marido o palhaço espanhol Pepe Nuñez.

O circo é a materialização de um projeto amadurecido ao longo de dez anos, e serve de palco permanente para as mais diversas manifestações artísticas. Tem como foco se tornar um dos espaços culturais independentes mais importantes de Santa Catarina.

Além de ser um centro de fomento e de intercâmbio entre artistas e produtores culturais, outra grande missão da estrutura é a preparação de novos talentos. As oficinas que Pepe ministra em todo o Brasil - ele é um dos mais respeitados e conhecidos formadores de palhaços no país, e de outros oficineiros reconhecidos no mundo da palhaçaria, se concentram, a partir de agora, em Florianópolis. Há também opções de curta duração e também cursos que se estenderão ao longo de quase um ano.

Tudo isso é feito com autonomia, independência e liberdade. Batizar o circo com a referência à Dona Bilica foi uma escolha natural: trata-se de uma homenagem à cultura local, com a qual Vandeca convive desde pequena - e cujos conhecimentos aprofundou nas intensas pesquisas que fez para desenvolver a personagem - e uma manifestação de agradecimento de Pepe à cidade que o acolheu. Dessa forma, a cultura açoriana é certamente uma referência constante para o circo.

Em relação a configuração física, o espaço também oferece oficina de acrobacia aérea, usando tecido acrobático, lira e trapézio. Com $1.404 \mathrm{~m}^{2}$, a estrutura inclui teatro para 225 pessoas equipado com caixa preta, iluminação cênica e sonorização, além de restaurante, escritório, loja de conveniências e estacionamento. 
O circo é um espaço de fomento a cultura e ao estômago. Além do foco principal que está nas apresentações musicais e teatrais/circenses que se apresentam de quinta a domingo no espaço, o mesmo conta com um restaurante com atuação na culinária espanhola e petiscos.

\subsection{AÇÕES DE MARKETING DO CIRCO DA DONA BILICA}

O desejo e materialização de ter um espaço cultural, atendeu a necessidade da Cia Pé de Vento Teatro, de ter um ambiente para ensaios e apresentações. E também de atender a uma necessidade, que ainda está em trâmite: o de criar o hábito de acessar a cultura por parte da população. Portanto as ações e estratégias de marketing são fundamentais ao funcionamento das atividades do Circo da Dona Bilica.

Conforme abordado por Branstad e Lucier (2001, apud LIMA et al, 2003, p. 17) a elaboração dos objetivos é um dos elementos do marketing estratégico, deve estar voltada por exemplo a uma entrega de valor, para o Circo da Dona Bilica, pode-se elencar estes como:

- Democratização da cultura, atingindo todas as camadas da sociedade, independentemente da idade, grau cultural ou econômico;

- Formação de público para cultura em Florianópolis;

- Fazer da cultura um produto de consumo.

A definição das estratégias adotadas servem como impulso para divulgação e promoção do Circo da Dona Bilica. A democratização da cultura, quer dizer sobre a pretensão de ampliar os bens culturais à comunidade. Com o espaço erguido e em atividade, a democratização se dá pela acessibilidade econômica, visto que os preços praticados estão abaixo do mercado cultural em Florianópolis. Com isto quebra-se um mito de que quem alimenta a cultura, a arte é a elite, e de que é possível e imprescindível a popularização da arte.

Com o acesso à cultura, há a exploração intelectual do espectador, gerando um entendimento mais intenso do produto cultural e assim são dados passos rumo à formação de público. Para isto é necessário fornecer uma programação intensa que atenda este público, com opções variadas de músicas, teatro, circo, artes visuais, entre outros. E a partir disto, enxerga-se a 
cultura como um momento de debates, conflitos, considerações, ponderações, onde o espectador é estimulado a questionar, descobrir suas motivações, e seus valores. Sensibiliza-se o expectador afim de que este, diante de tantas indagações, consiga ter o suporte necessário para a descoberta do seu curso, explorando cada vez mais seu lado intelectual.

O conceito de promoção conforme visto por Honorato (2004) é o processo de comunicação, que vise influenciar o cliente na compra. O Circo da Dona Bilica usa de ações de marketing para a venda dos espetáculos, que também são usadas em qualquer outro segmento na promoção do seu produto/serviço. Isto porque se fala neste caso da cultura como um produto de consumo, visto que o seu valor social é reproduzido de acordo com o tempo, diferente de outros produtos, que se esgotam mediante o seu consumo.

O espaço, na busca da aproximação do contato com o seu cliente, utiliza como meios de comunicação o uso de redes sociais, sendo a principal o Facebook. Mensalmente produz um material gráfico impresso como cartazes, folders, faixa e banner. Estes materiais são distribuídos em pontos comerciais na região, e também para empresas parceiras do Circo da Dona Bilica. O Circo conta com o apoio de algumas empresas que empregam este apoio através de permuta, ou apoio financeiro.

São abordados os espectadores que vão ao Circo, e os mesmos preenchem uma ficha de cadastro (com nome, e-mail, e se há o interesse por oficinas). Após a coleta destes dados, são criados mailling, e enviados a programação semanal do Circo. Hoje o espaço já conta com mais de 1.500 e-mails cadastrados.

Além do processo de comunicação, o Circo da Dona Bilica desenvolve o projeto "A Escola vai ao Circo". Neste projeto, escolas particulares e públicas de Florianópolis e região são contatadas para trazerem os alunos ao espaço, e assistirem a um dos espetáculos que estão pré programados.

As apresentações abordam diversos temas, onde muito deles tem relação com os estudos das salas de aula como a preservação e conhecimento da tradição açoriana, e a conscientização ambiental. Também há o estímulo através do exercício lúdico com espetáculos de palhaços em cena. Neste projeto, são praticados valores de ingressos para o espetáculo, e também oferecidos um pacote de pipoca na compra, este último caso opcional. 


\subsection{ESTRATÉGIAS DE MARKETING DO CIRCO DA DONA BILICA}

O Circo da Dona Bilica, enquanto espaço cultural, adota estratégias mercadológicas, com vistas a atingir seus objetivos estabelecidos, de consolidar a imagem de espaço cultural, de atrair o público e democratizar a cultura. Desta forma, necessita determinar o público alvo ao qual estava se direcionando. A segmentação deste público se dá em conformidade com a visão tradicional apontada por Honorato (2004) que, neste caso, pode ser classificada em espectadores da Grande Florianópolis, e que atendam as classes B e C. Isto porque um de seus objetivos diz respeito a democratização da cultura, através de sua valorização.

E na busca pelo melhor entendimento do perfil deste público observa-se o exposto por Kotler e Armstrong (2004) sobre a escolha de um ou mais segmentos possíveis dentro do mercado. Para o Circo da Dona Bilica, os tipos de predisposição que uma pessoa possui para participar da vida cultural, são as que: não estão inclinados a participar, os inclinados ou predispostos a participar, e, os que já participam, como abordado por Rand (2001, apud LIMEIRA; GOUVEIA, 2008, p. 26).

Estas categorias, em junção com a segmentação do público alvo estabelecido para o Circo da Dona Bilica, permite que seja criado o posicionamento para seu negócio, e quais as estratégias a ser estabelecidas para atingi-los. Assim, há a construção da imagem, que neste caso, é o de se tornar referência como espaço Cultural em Florianópolis.

Em concordância ao conceito de Kotler e Armstrong (2004), onde afirma que o posicionamento, é a construção da imagem que um produto representa na mente do consumidor. Buscou-se elaborar para o Circo da Dona Bilica, através do mix de marketing, que são as variáveis que podem ser controladas e moldadas para atender a demanda de um produto, composto pelos 4P's, segundo Cobra (2009): produto, preço, praça e promoção.

O produto, sendo "bem físico ou um serviço com um conjunto de características que é destinado a um segmento de mercado identificado" (FERREIRA; REIS; SERRA, 2010, p. 371). Neste caso o fornecido pelo Circo da Dona Bilica, trata-se da prestação de um serviço, de um espaço físico que serve para sediar apresentações de teatro, circo e música. O espaço também dispõe do restaurante especializado na culinária espanhola e petiscos. Também oferece aulas de acrobacia aérea (acrobacia através de lira, tecido e trapézio) para adultos e crianças. Conta com 
uma loja, que vende camisetas personalizadas, produtos artesanais, CD, DVD de artistas que já passaram pelo espaço, entre outros produtos. E por fim, as oficinas especializadas na arte clown, para àqueles que queiram se especializar no ofício do palhaço como profissão.

Ferreira, Reis e Serra (2010) abordaram que o preço é o valor monetário destinado para um bem ou serviço. Para o Circo da Dona Bilica, o mesmo pratica preços populares, quando comparado a outras opções culturais que estão disponíveis na cidade. Com o valor de vinte reais para o ingresso na modalidade inteira e dez reais para meia entrada conforme situações na legislação (estudantes, idosos, crianças e professores da rede de Florianópolis). O Circo trabalha com pagamento à vista e como meios de pagamento são aceitos, dinheiro, e cartão de débito e crédito.

Quanto à praça, conforme visto em Kotler e Keller (2006), onde diz respeito aos canais de distribuição utilizados para atingir o mercado-alvo. O espaço Cultural Circo da Dona Bilica, tem um canal único, onde o cliente deve ir até o mesmo. Está localizado no bairro Morro das Pedras, Sul da Ilha de Florianópolis. Não há uma mensuração exata da proporção do público atuante de acordo com a região, mas estima-se que grande parte seja moradores da própria região Sul. Cabe ressaltar que o mesmo também recebe espectadores de cidades vizinhas como Palhoça e São José.

No período de janeiro, com uma grande vinda de turistas no período de férias, muitas famílias de outras cidades e estados, e também outros países, vieram conhecer o Circo da Dona Bilica. O espaço é recente, e janeiro de 2014 foi a primeira experiência com este período de sazonalidade que o turismo de Florianópolis enfrenta. Desta forma, espera-se que o crescente reconhecimento que o Circo vem obtendo, reflita-se em um número maior de visitantes no período de férias da próxima temporada, principalmente janeiro e fevereiro.

Uma das maiores dificuldades apresentadas, talvez esteja na distância do espaço da região central de Florianópolis. A região sul apresenta uma grande dificuldade na parte de acesso em se tratando dos horários de ônibus, que em sua maior parte são reduzidos.

A promoção, em consonância ao conceito de Honorato (2004) diz respeito às ações que o Circo usa na comunicação, de modo a influênciar o cliente para compra. O Circo usa como estratégias de comunicação, o uso de redes sociais, como o Facebook e Google+. Também possui um sítio de internet www.circodonabilica.com.br, onde são divulgadas, a programação do espaço, 
informações sobre as oficinas ministradas, restaurante, e ainda sobre a disponibilidade de locação da estrutura para eventos. O espaço também realiza a venda de ingressos pela internet, através do site www.nosvamos.com.br. E como já mencionada a impressão de material gráfico, como Folders, em torno de 10.000 unidades, cartazes, baner e faixa. Usa-se do envio de mailling aos clientes cadastros em nossa mala direta. O espaço também fornece a programação mensal para sites que são parceiros na divulgação da programação da cidade, como em Florianópolis, há o exemplo do Guia Floripa ${ }^{1}$.

\section{CONCLUSÃO}

Com a pretensão de se obter informações de como podem ser percebidas as ações de marketing no Circo da Dona Bilica, inicialmente foi estabelecida uma abordagem sobre os fundamentos conceituais ligados ao marketing, ao marketing estratégico e sobre o posicionamento. Estes conceitos expostos permitiram um maior entendimento do problema da pesquisa, e assim serviu de base para estrutura de toda a análise deste artigo.

O levantamento destas informações possibilitou o alcance dos objetivos descritos no artigo. A caracterização do Circo da Dona Bilica como uma organização cultural foi realizada através de todo o conceito histórico e as atividades desempenhadas por ela. A descrição da fundamentação teórica sobre o marketing trouxe uma explanação para que pudessem ser enumeradas as ações de marketing dentro do Circo. A análise de marketing do Circo como espaço cultural possibilitou o entendimento dos conceitos de posicionamento, o mesmo pode ser direcionado ao Circo.

O marketing do Circo da Dona Bilica pode ser percebido à partir dos referenciais de cultura e ações mercadológicas que são desenvolvidas pelo próprio espaço. Pode-se concluir em atendimento aos objetivos propostos neste trabalho, que o Circo da Dona Bilica apresenta-se dentro do mercado como uma organização que depende de ações estratégicas de marketing para o seu desenvolvimento, tanto como negócio como espaço cultural.

A adoção de medidas para promoção deste espaço cultural demonstra a predisposição de tornar a cultura como um produto de consumo. $\mathrm{O}$ incentivo às iniciativas propostas vem a criar dentro da sociedade, um novo espaço para debates, reflexões. Assim, há o fomento para a valorização da cultura no processo de formação do individuo.

Linguagens - Revista de Letras, Artes e Comunicação ISSN 1981-9943 Blumenau, v. 9, n. 2, p. 190-210, mai./ago. 2015 
Também se pode concluir sobre a importância deste trabalho ao pesquisador, que poderá desempenhar as atividades dentro do Circo, visando o seu melhor posicionamento de modo mais eficaz. Hoje as ações adotadas são importantes para o andamento dos negócios, conforme mencionado.

Esta pesquisa teve uma limitação no sentido do seu desenvolvimento estar ligado ao trabalho qualitativo. Portanto, sugere-se uma pesquisa mais aprofundada de cunho quantitativo, afim de uma mensuração aproximada com números e estatísticas específicos ao mercado alvo a ser posicionado pelo espaço. Visto que o trabalho desenvolvido, teve um maior aprofundamento teórico, que serviu de base para responder aos problema de pesquisa, e atendimento aos objetivos.

\section{NOTAS}

1 Dados disponíveis no site do Guia Floripa em <http://www.guiafloripa.com.br/servicos/arte-ecultura/centro-espaco-cultural/circo-da-dona-bilica.htm>

\section{REFERÊNCIAS}

ALMEIDA, C.J.M. Antecedentes do marketing cultural. Associação brasileira de gestão cultural: atividades, 2013. Disponível em: http://abgc.org.br/wp-content/uploads/2013/03/1marketingcultural-candido.pdf. Acesso em 24 de setembro de 2014.

CHIAVENATO, I. Administração: teoria, processo e prática. 4. ed. Rio de Janeiro: Elsevier, 2007.

CHIAVENATO, I. Introdução a teoria geral da administração. 5. ed. atual. Rio de Janeiro: Campus, 1999.

COBRA, M. Administração de marketing no Brasil. 3. ed. São Paulo: Elsevier, 2009.

CORREA, J. et. al. Marketing a teoria e a prática. Rio de Janeiro: Senac, 2009.

CRUZ, C; RIBEIRO, U. Metodologia científica: teoria e prática. Rio de Janeiro: Axcel Books, 2003.

FERNANDES, D. R. A utilização do marketing operacional como instrumento de gestão nas micro e pequenas empresas industriais. Revista da FAE, Curitiba, v. 6, n. 1, p. 53-64, jan./abr. 2003.

GIDDENS, A. Sociologia. 4. ed. Porto Alegre: Artmed, 2005. 
GOMES, M; KURY, G. A evolução para o marketing 3.0: o marketing de causa. Fortaleza: Universidade de Fortaleza, 2013. Disponível em: http://portalintercom.org.br/anais/nordeste2013/ resumos/R37-0945-1.pdf. Acesso em 16 de novembro de 2014.

HOFFMANN, S.M.R; SILVA, F.M.V; DELLAGNELO, E.H.L. Objetivos de organizações culturais e suas fontes financiadoras. Rio de Janeiro: cadernos Ebape, 2009.

HONORATO, G. Conhecendo o marketing. Barueri: Manole, 2004.

KOBAYASHI, A.R.M; ARO, E.R. Análise de estratégias sob o enfoque de marketing 3.0 e a vantagem competitiva sustentável: estudo de caso Natura. Cuiabá: Universidade de Mato Grosso, 2014. Disponível em: http://www.convibra.com.br/upload/paper/2014/32/2014_32_9227.pdf. Acesso em 16 de novembro de 2014.

KOTLER, P.; KARTAJAYA, H.; SETIAWAN, I. Marketing 3.0: as forças que estão definindo o novo marketing centrado no ser humano. 4. Reimpressão. Rio de Janeiro: Campus, 2010.

KOTLER, P; KELLER, K. L. Administração de marketing: a bíblia do marketing. 12 ed. São Paulo: Pearson Pretice Hall, 2006.

KOTLER, P; ARMSTRONG, G. Princípios de marketing. 9. ed. São Paulo: Prentice Hall, 2003.

LIMA, M. et al. Gestão de marketing. Rio de Janeiro: Editora FGV, 2003.

LIMEIRA, T.M.V; GOUVEIA, M.A.M. Segmentos populares, consumo e participação cultural. São Paulo: Fundação Getúlio Vargas, 2008.

MACARIO, C. Palhaçaria com sotaque mané. Jornal diário catarinense: Anexo [versão impressa]. Florianópolis: Diário Catarinense, 23 ago. 2014.

MARCO, K. A profissionalização dos setores culturais. [Rio de Janeiro]: Associação Brasileira de Gestão Cultural, 2007. Disponível em: http://abgc.org.br/wp-content/uploads/2013/03/ setoresculturais-KatiadeMarco.pdf. Acesso em 01 de agosto de 2014.

MARCONI, M.A; LAKATOS, E.M. Metodologia de trabalho científico. 6 ed. rev. São Paulo: Atlas, 2001.

MATOS, J.G. et al. Análise do ambiente corporativo: do caos organizado ao planejamento estratégico das organizações. Rio de Janeiro: E-papers, 2007. Disponível em: http://books. google.com.br/books?id=dOjjvV1m7k0C\&printsec=frontcover\&hl=pt-BR\&source=gbs_ge_sum mary_r\&cad $=0 \# \mathrm{v}=$ onepage $\& \mathrm{q} \& \mathrm{f}=$ false. Acesso em 15 de setembro de 2014 .

MIYASHITA, M. Marketing que faz a diferença. [S.1.]. jun. 2006. Disponível em: http://www.portaldomarketing.com.br/Artigos/Marketing_que_faz_a_diferenca.htm. Acesso em 14 de setembro de 2014. 
NETO, M.M.M. Marketing para as artes: a evolução do conceito de marketing cultural e a importância desse campo de atuação para o profissional de relações públicas. Organicom, v. 3, n. 5, 2006, pp. 108-119. Disponível em: http://revistaorganicom.org.br/sistema/index.php/ organicom/article/view/74/207. Acesso em 24 de setembro de 2014.

PRIDE, M; FERREL, O.C. Marketing conceitos e estratégias. 11. ed. Rio de Janeiro: LTC Editora, 2001.

SANTIAGO, M.P. Administração de marketing. Curitiba: IESDE Brasil S.A., 2009.

SILVA, E. L; MENEZES, E.M. Metodologia da pesquisa e elaboração de dissertação. 4. ed. rev. atual. Florianópolis: UFSC, 2005. Disponível em: https://projetos.inf.ufsc.br/arquivos/ Metodologia_de_pesquisa_e_elaboracao_de_teses_e_dissertacoes_4ed.pdf. Acesso em 01 de outubro de 2014.

SILVA, H.H. Planejamento estratégico de marketing. 3. ed. Rio de Janeiro: Editora FGV, 2006.

SILVA, R.O. Teorias da administração. São Paulo: Pioneira Thomson Learning, 2001.

TERENCE, A.C.F. Planejamento estratégico como ferramenta de competitividade na pequena empresa: desenvolvimento e avaliação de um roteiro prático para o processo de elaboração do planejamento. São Carlos: Universidade de São Carlos, 2002. Disponível em: $<$ http://www.teses.usp.br/teses/disponiveis/18/18140/tde-27052004-110812/en.php>. Acesso em 12 de novembro de 2014.

VALENTE, R. et al. Gestão de organizações culturais. [São Paulo], 2007. Disponível em: $<$ http://rae.fgv.br/sites/rae.fgv.br/files/artigos/10.1590_S0034-75902007000200011.pdf>. Acesso em 24 de setembro de 2014. 